\title{
Acne Inversa-like Lesions Induced by a Low Dose of Sorafenib
}

\author{
Javier Aubán-Pariente ${ }^{1}$, Laura Palacios-García ${ }^{1}$, Cristina Galache-Osunaํㅜ, Marc Mir-Bonafée \\ Patricia Morales Del Burgo ${ }^{2}$, Jorge Santos-Juanes ${ }^{1}$
}

1 Department of Dermatology, Central University Hospital of Asturias, Oviedo, Spain

2 Department of Pathology, Central University Hospital of Asturias, Oviedo, Spain

Key words: acne inversa, sorafenib, cutaneous adverse reactions, dermatopathology

Citation: Aubán-Pariente J, Palacios-García L, Galache-Osuna C, Mir-Bonafé M. Morales Del Burgo P, Santos-Juanes J. Acne inversa-like lesions induced by a low dose of sorafenib. Dermatol Pract Concept. 2021;11(2):e2021008. DOI: https://doi.org/10.5826/dpc.1102a08

Accepted: July 29, 2020; Published: March 8, 2021

Copyright: (02021 Aubán-Pariente et al. This is an open-access article distributed under the terms of the Creative Commons Attribution License BY-NC-4.0, which permits unrestricted noncommercial use, distribution, and reproduction in any medium, provided the original author and source are credited.

Funding: None.

Competing interests: The authors have no conflicts of interest to disclose.

Authorship: All authors have contributed significantly to this publication.

Corresponding Author: Javier Aubán-Pariente, MD, Central University Hospital of Asturias, Dermatology Department, Av. Roma, s/n, 33011 Oviedo, Spain. Tel. 34-985108000. Email: javiauban@gmail.com

\section{Introduction}

Sorafenib is an oral multikinase inhibitor approved for the treatment of unresectable hepatocellular carcinoma, differentiated thyroid cancer, and advanced renal-cell carcinoma. This drug blocks tumor cell proliferation and angiogenesis by inhibiting the Raf serine/threonine kinases (RAF1 and BRAF) as well as multiple receptor tyrosine kinases [1]. Adverse skin reactions occur in up to $90 \%$ of patients. Although acneiform eruptions have been widely reported in association with epidermal growth factor receptor (EGFR) inhibition, ranging from $24 \%-91 \%$ of patients, those induced by sorafenib are rare. They usually appear in the first 6 weeks after drug onset and are located on the face. Regarding clinical-pathological characteristics, acneiform eruptions induced by sorafenib are classified into 3 groups: papulopustular eruptions without associated retention lesions, nodular-cystic eruptions, and perforating folliculitis [2]. Of these groups, papulopustular facial eruptions have been the most frequently observed. Here we report a case of acne inversa-like lesions induced by a low dose of sorafenib in a 62-year-old man with hepatocellular carcinoma.

\section{Case Presentation}

A 62-year-old man was referred to us for evaluation of 2 exudative lesions on his lower extremities of 1-month duration. His medical history included sorafenib $400 \mathrm{mg} /$ day for 4 months for diffuse hepatocellular carcinoma. The patient denied a history of similar lesions prior to the onset of sorafenib. Physical examination revealed 2 indurated erythematous plaques on both thighs that were 2 to $6 \mathrm{~cm}$ in diameter (Figure 1, A and B). The lesions had small oozing cavities, fistulous tracts, and depressed scar areas. No involvement of other locations was observed.

Skin swabs for viral and bacterial cultures were negative. A skin biopsy showed perifollicular and perivascular lymphohistiocytic infiltration (Figure 2A). Dilated follicular infundibula were filled with compact parakeratotic cornified cells and neutrophils (Figure 2B). A diagnosis of acne inversa-like lesions induced by sorafenib was made, and topic 


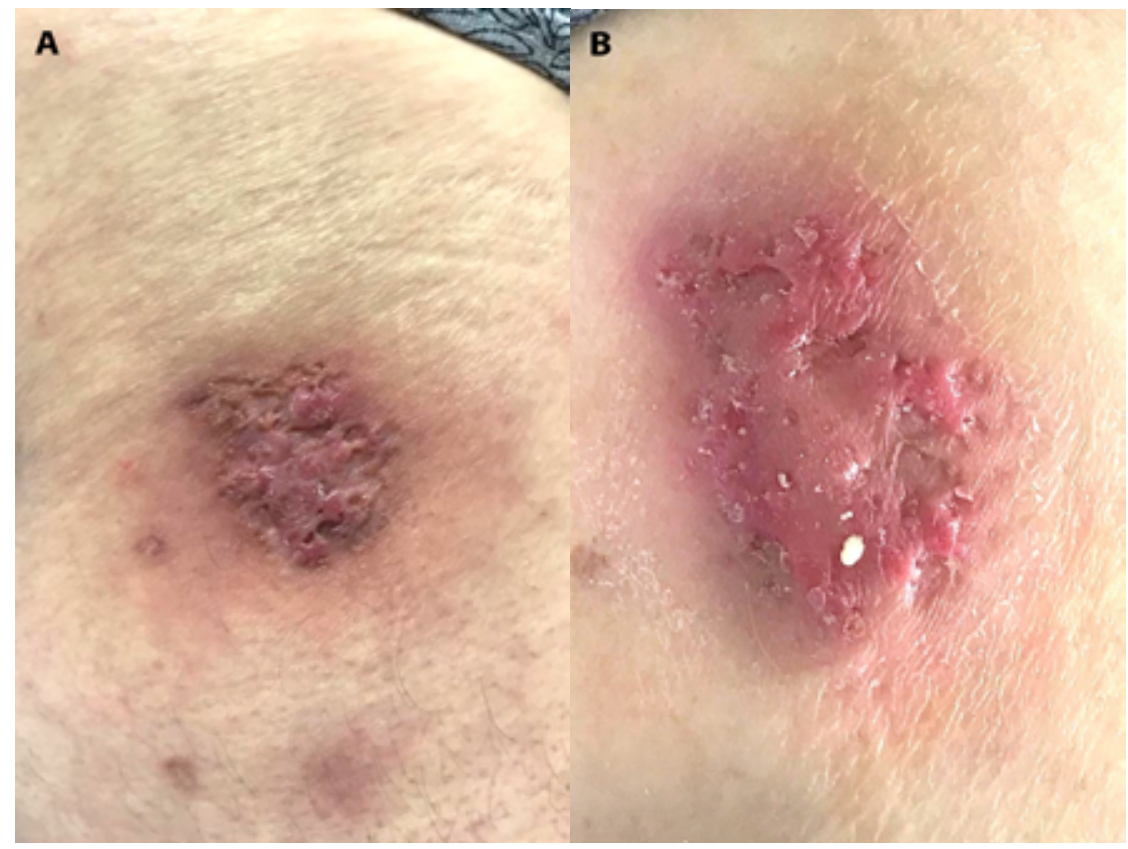

Figure 1. (A, B) Two indurated erythematous plaques with fistulous tracts and depressed scar areas on both legs.

A

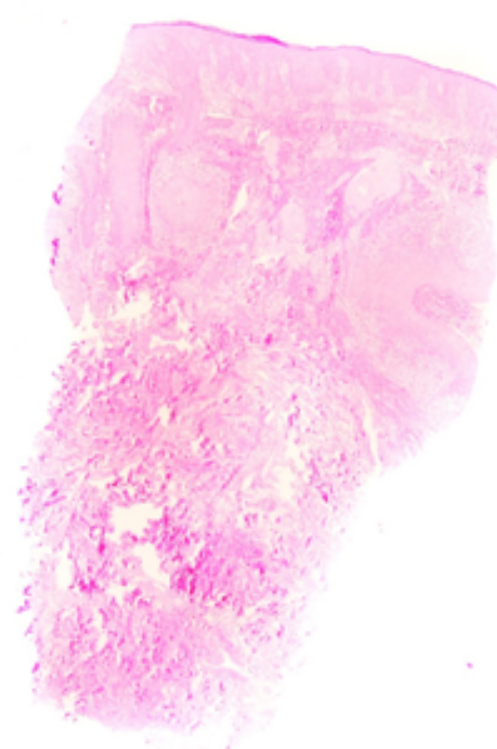

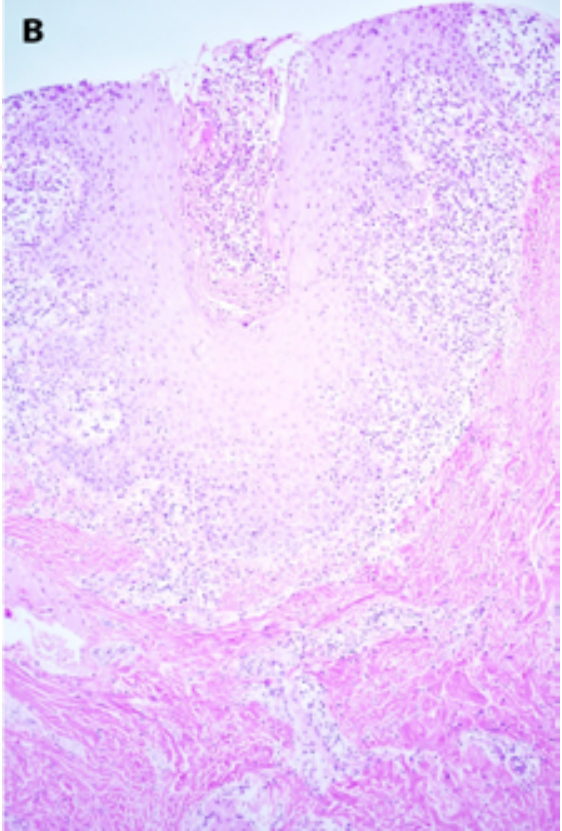

Figure 2. (A) Perifollicular and perivascular lymphohistiocytic infiltration $(H \& E, \times 20)$. (B) Dilated follicular infundibula filled with compact parakeratotic cornified cells and neutrophils $(\mathrm{H} \& \mathrm{E}, \times 100)$. fusidic acid was prescribed twice a day. The oncologist temporarily discontinued treatment with sorafenib due to liver decompensation. After 1 month of sorafenib interruption, there was complete resolution of the eruption with mild scarring.

\section{Conclusions}

Five cases of acne inversa-like lesions associated with sorafenib have been reported, all of them in males [1,2]. Clinical features of 4 of these patients were similar to the case presented here, and except for 1 case of classic hidradenitis suppurativa located in the bilateral axillae and inguinal region, the localization was atypical in affecting the legs, abdomen, or buttocks. Histopathological analysis showed comedone-like follicular dilatation with perifollicular lymphohistiocytic infiltration. There appears to be a dose-dependent relationship between sorafenib and acneiform reaction. Except in 1 case in which an acne inversa-like eruption resolved spontaneously, lesions only improved with dose reduction or treatment interruption in combination with topical retinoids, antibiotics, or benzoyl peroxide [1,2].

If we apply the Naranjo drug reaction assessment tool to this case, the result would be "probable." Unlike previously reported cases, our patient developed acneiform lesions while on a low dose of $200 \mathrm{mg}$ twice a day. Further studies are needed to elucidate the pathogenic explanation and dose relationship between sorafenib and acne inversa-like lesions.

\section{References}

1. Pichler M, Carriere C, Mazzoleni G, Kluge R, Eisendle K. Acne inversa-like lesions associated with the multi-kinase inhibitor sorafenib. Clin Exp Dermatol. 2014;39(2):232-233. DOI: 10.1111/ ced.12257. PMID: 24330088.
2. Borgia F, Saitta C, Vaccaro M, Franzè MS, Lentini M, Cannavò SP. Nodular-cystic eruption in course of sorafenib administration for hepatocarcinoma: an unconventional skin reaction requiring unconventional treatment. Int J Immunopathol Pharmacol. 2017;30(3):327-331. DOI: 10.1177/0394632017727618. PMID: 28825507. 